\title{
Epidural spinal cord stimulation for the control of spasticity in spinal cord injury patients lacks long-term efficacy and is not cost-effective
}

\author{
Meena Midha and James K Schmitt \\ Spinal Cord Injury Service and General Internal Medicine Section, Hunter Holmes McGuire Veterans Administration \\ Medical Center, Richmond, Virginia, USA
}

\begin{abstract}
Epidural spinal cord stimulation has been used to decrease spasticity and spasms in spinal cord injury patients. However, the long-term benefits of this procedure have not been determined. We therefore conducted a retrospective study of the possible long-term efficacy of the epidural spinal cord stimulator for the relief of symptoms. Seventeen patients were identified who had undergone implantation of an epidural spinal stimulator. The total number of implantations in these seventeen patients was 24 , (seven patients had undergone a second implantation) costing a total of $\$ 566400$. In only one of the patients was the epidural stimulator providing symptomatic relief. The epidural spinal cord stimulator lacks long-term efficacy for the relief of spasticity and pain and is not cost effective.
\end{abstract}

Keywords: epidural stimulator; spinal cord injury; spasticity

\section{Introduction}

Spasticity and spasms are forms of increased muscle tone frequently encountered as sequelae of spinal cord injury. ${ }^{1,2}$ Spasms are often associated with pain. ${ }^{3}$ Over $90 \%$ of spinal cord injury patients experience muscle spasms and up to $25 \%$ of spasms are severe and do not respond to medical therapy. ${ }^{4}$

There are many treatments for spasms in SCI patients: anti-spasmodic medication, nerve blocks, intrathecal baclofen infusion, and intrathecal phenol blocks, have been employed. ${ }^{5}$ In addition surgical treatments such as myelotomy, rhizotomy, and epidural spinal stimulation have been utilized to treat spasticity.

Epidural spinal cord stimulation has been found to relieve spasms in patients with multiple sclerosis, ${ }^{6}$ extrapyramidal motor disorders, ${ }^{7}$ spasmodic torticollis $^{8}$ and spinal cord injury. ${ }^{9}$ The mechanism of action of spinal cord stimulation for the relief of spasticity is uncertain. However, it is possible that spinal cord stimulation inhibits hyperexcitable spinal circuits, which are normally inhibited by higher neurological centers. ${ }^{8}$

Spasticity and spasms in spinal cord injury patients are chronic disorders, lasting many years. Although epidural spinal stimulation has been shown to produce immediate short-term relief of spasticity and spasms, there are no reports of the possible efficacy of epidural spinal cord stimulation in producing long-term relief of spasticity and spasms in spinal cord injury patients.

The following study was conducted to determine the long-term efficacy of epidural spinal stimulation for

Correspondence: Dr Meena Midha the relief of spasticity and pain in spinal cord injury patients.

\section{Methods}

The study was conducted between 1993 and 1995 . Twenty-nine patients underwent implantation of an epidural stimulator between 1986 and 1988. Prerequisites for implantation were: spinal cord injury of at least 6 months duration, presence of severe handicapping spasms, unsatisfactory response to an adequate trial of antispasmodic medication. An attempt to contact all patients who had undergone the procedure was made. Seventeen patients were located. The characteristics of the patients are summarized in Table 1. The mean interval between implantation of the stimulator and the injury was 7 years (range $0.5-30$ years).

The patients were contacted in person or by telephone and were asked to quantitate in a scale from 0 to 10 (with 10 being total symptom relief) the decrease in symptoms with the epidural stimulator. They were also asked how long they had had the symptom relief since the time of the implantation.

\section{Results}

Seventeen patients were identified who had undergone an implantation with an epidural stimulator. Of these patients, ten had an implanted unit at the time of the study. Reasons for removal of units were infection at the surgical site in one patient and lack of symptom relief or an actual increase in spasticity and pain with the epidural unit in the other patients. Seven patients 
Table 1 Characteristics of patients undergoing epidural stimulator implantation

\begin{tabular}{|c|c|c|c|c|c|}
\hline & Age & Cord level & $\begin{array}{l}\text { Epidural s } \\
\text { Injury date }\end{array}$ & $\begin{array}{l}\text { dy } \\
\qquad \begin{array}{l}\text { Date of } \\
\text { original implantation }\end{array}\end{array}$ & $\begin{array}{c}\text { Reason } \\
\text { for implantation }\end{array}$ \\
\hline 1 & 32 & $\mathrm{C} 4 / 5$ com. & $4 / 17 / 82$ & $7 / 15 / 86$ & Spasm \\
\hline 2 & 37 & C5/6 com. & $6 / 12 / 86$ & $1 / 9 / 87$ & Spasm \\
\hline 3 & 50 & $\mathrm{C} 4$ inc. & $9 / 7 / 86$ & $4 / 14 / 87$ & Spasm \\
\hline$* 4$ & 31 & C5 inc. & $6 / 3 / 84$ & $11 / 17 / 87$ & Pain \& spasm \\
\hline 5 & 41 & T7 inc. & $6 / 25 / 76$ & $11 / 17 / 87$ & Spasm \\
\hline *6 & 36 & C4 inc. & $9 / 8 / 79$ & $5 / 1 / 86$ & Spasm \\
\hline$* 7$ & 31 & T5 com. & $12 / 12 / 84$ & $10 / 7 / 86$ & Spasm \\
\hline 8 & 47 & C5 com. & $9 / 7 / 82$ & $4 / 5 / 88$ & Pain \& spasm \\
\hline 9 & 39 & T4 com. & $11 / 11 / 82$ & $7 / 18 / 88$ & Spasm \\
\hline 10 & 29 & C5/6 cinc. & $6 / 12 / 86$ & $2 / 2 / 88$ & Spasm \\
\hline 11 & 72 & $\mathrm{C} 4 / 5$ inc. & $4 / 28 / 87$ & $10 / 20 / 87$ & Spasm \\
\hline$* 12$ & 45 & T3/4 com. & $2 / 6 / 83$ & $12 / 15 / 87$ & Spasm \\
\hline 13 & 62 & T4 com. & $5 / 19 / 58$ & $5 / 10 / 88$ & Pain \& spasm \\
\hline$* 14$ & 46 & T7 com. & $1 / 29 / 66$ & $11 / 3 / 87$ & Spasm \\
\hline$* 15$ & 40 & C5/6 com. & $11 / 9 / 84$ & $2 / 15 / 86$ & Spasm \\
\hline$* 16$ & 59 & $\mathrm{~T} 10$ inc. & $10 / 21 / 85$ & $8 / 8 / 87$ & Pain \& spasm \\
\hline 17 & 63 & T7 com. & $5 / 11 / 59$ & $7 / 8 / 86$ & Pain \& spasm \\
\hline
\end{tabular}

Asterisks indicate two implantations

had undergone two epidural stimulator implantations (Table 1). In each of these patients the second unit was inserted because of failure of the original unit. At the time of the study only one patient (patient number one) reported that the epidural stimulator was producing symptomatic relief. All other patients felt that the unit was ineffective. The average length of time that all units produced symptomatic relief was 6 months (range $0-96$ months). In 9 implantations there was failure of the unit from the day of implantation. In the fourteen units that were removed the average time from unit implantation to removal was 3.4 years (range 5 days -7 years).

\section{Discussion}

This study suggests that the epidural spinal stimulator, although initially successful in controlling spasticity and pain, lacks long-term efficacy in controlling symptoms in spinal cord injury patients. Why this unit fails to produce long-term relief is uncertain. The possibility of dislodgment of the electrode seems unlikely as replacement of the unit in subjects in whom the original unit failed also did not relieve symptoms. It is possible that long-term use of the unit produces tachyphylaxis to electrical stimulation. In cases in which the unit failed, an increasing voltage was applied to the unit until a motor threshold was exceeded and muscle contraction was produced. Thus failure of the unit to stimulate the spinal cord seems to be an unlikely explanation. Regardless of the reason for failure and difficulties of quantifying pain and spasticity, 16 out of 17 patients felt that the epidural spinal stimulator did not produce symptomatic relief, or that the cost and discomfort of a second implantation was not worth any potential benefit.
The approximate cost of an epidural stimulator (including generator, leads, extension kit and screening device) is $\$ 9600$. Physician fees, operating room and surgical intensive care unit costs and miscellaneous costs associated with hospitalization for implantation are about $\$ 14000$ per patient. The total cost of implantation per patient, not including follow-up care is therefore $\$ 23600$. Therefore the approximate cost of all 24 implantations was \$566 400 .

Although the epidural spinal stimulator was initially successful in controlling spasms in certain patients, by an average time of 6 months from implantation only one of 17 patients was being successfully treated by the simulator.

The high cost and low efficacy would suggest that this procedure is not cost effective. The more conventional methods of spasm control should be utilized. Only in cases in which other methods of control of symptoms fail should the epidural stimulator be considered.

\section{Acknowledgements}

Presented in part at the 35 th meeting of the International Society of Paraplegia, Atlanta, GA, August 18-20, 1996. We wish to acknowledge Rich Wilhoite for assisting with collection of data.

\section{References}

1 Barolat G, Maiman D. Spasms in spinal cord injury. A study of 72 patients. J Am Paraplegia Soc 1987; 10: 25-38.

2 Young RR. Treatment of spastic paresis. N Engl J Med 1984; 320: $1553-1555$

3 Barolet $\mathrm{G}$. The surgical management of spasticity and spasms in spinal cord injury. An overview. J Am Paraplegia Soc 1988; 2: 9 13. 
4 Cioni B, Meglio M, Pentimalli L, Visocchi M. Spinal cord stimulation in the treatment of paraplegic pain. $J$ Neurosurg 1995; 82: $35-39$.

5 Young R. Spastic Paresis. In: Young RR and Woolsey RM (eds). Diagnosis and Management of Disorders of the Spinal Cord. WB Saunders, Philadelphia 1995, pp 363-376.

6 Cook AW, Weinstein SP. Chronic dorsal column stilulation in multiple sclerosis. Preliminary report NY State J Med 1973; 73: $2868-2872$
7 Waltz JM. Computerized multi-level spinal cord stimulation in motor disorders. Appl Neurophysiol 1978; 45: 73-92.

8 Gildenberg PL. Treatment of spasmodic torticollis by dorsal column stimulation. Appl Neurophysiol 1978; 41: 113-121.

9 Barolat-Romana $\mathrm{G}$ et al. Immediate effects of spinal cord stimulation in spinal spasticity. J Neurosurg 1985; 62: $558-562$. 